\title{
BMJ Open Using a mass media campaign to raise women's awareness of the link between alcohol and cancer: cross-sectional pre-intervention and post-intervention evaluation surveys
}

\author{
Helen G Dixon, ${ }^{1}$ Iain S Pratt, ${ }^{2}$ Maree L Scully, ${ }^{1}$ Jessica R Miller, ${ }^{3}$ Carla Patterson, ${ }^{3}$ \\ Rebecca Hood, ${ }^{3}$ Terry J Slevin ${ }^{2}$
}

To cite: Dixon HG, Pratt IS, Scully ML, et al. Using a mass media campaign to raise women's awareness of the link between alcohol and cancer: cross-sectional pre-intervention and postintervention evaluation surveys. BMJ Open 2015;5: e006511. doi:10.1136/ bmjopen-2014-006511

- Prepublication history for this paper is available online. To view these files please visit the journal online (http://dx.doi.org/10.1136/ bmjopen-2014-006511).

Received 1 September 2014 Revised 23 December 2014 Accepted 7 February 2015

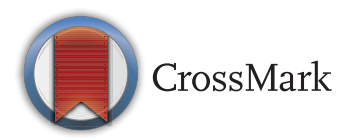

${ }^{1}$ Centre for Behavioural Research in Cancer, Cancer Council Victoria, Melbourne, Victoria, Australia

${ }^{2}$ Cancer Council Western Australia, Shenton Park, Western Australia, Australia ${ }^{3}$ Drug and Alcohol Office, Government of Western Australia, Mount Lawley, Western Australia, Australia

Correspondence to lain S Pratt;

SPratt@cancerwa.asn.au

\section{ABSTRACT}

Objectives: To evaluate the effectiveness of a population-based, statewide public health intervention designed to improve women's awareness and knowledge of the link between alcohol and cancer.

Design: Cross-sectional tracking surveys conducted pre-intervention and post-intervention (waves I and III of campaign).

Setting: Western Australia.

Participants: Cross-sectional samples of Western Australian women aged 25-54 years before the campaign $(n=136)$ and immediately after wave I $(n=206)$ and wave III $(n=155)$ of the campaign. Intervention: The 'Alcohol and Cancer' mass media campaign ran from May 2010 to May 2011 and consisted of three waves of paid television advertising with supporting print advertisements.

Main outcome measures: Campaign awareness; knowledge of drinking guidelines and the link between alcohol and cancer; intentions towards drinking.

Results: Prompted recognition of the campaign increased from $67 \%$ following wave I to $81 \%$ following wave III (adjusted OR (adj OR) $=2.31,95 \% \mathrm{Cl} 1.33$ to $4.00, p=0.003$ ). Improvements in women's knowledge that drinking alcohol on a regular basis increases cancer risk were found following wave I (adj $\mathrm{OR}=2.60$, $95 \% \mathrm{Cl} 1.57$ to $4.30, \mathrm{p}<0.001)$ and wave III (adj OR=4.88, $95 \% \mathrm{Cl} 2.55$ to $9.36, p<0.001$ ) compared with baseline. Knowledge of the recommended number of standard drinks for low risk in the long term increased between baseline and wave I $(\mathrm{adj} \mathrm{OR}=1.68$, $95 \% \mathrm{Cl} 1.02$ to 2.76, $\mathrm{p}=0.041$ ), but not baseline and wave III (adj OR=1.42, 95\% $\mathrm{Cl} 0.84$ to 2.39, $\mathrm{p}=0.191$ ). Among women who drink alcohol, the proportion expressing intentions to reduce alcohol consumption increased significantly between baseline and wave III (adj OR=2.38, 95\% $\mathrm{Cl} 1.11$ to 5.12 , $p=0.026)$. However, no significant reductions in recent drinking behaviour were found following the campaign.

Conclusions: Results indicate a population-based mass media campaign can reach the target audience and raise awareness of links between alcohol and

\section{Strengths and limitations of this study}

- This is the first published evaluation of a mass media campaign highlighting the link between alcohol and cancer.

- Results indicate this innovative mass media intervention produced medium to large effects on improving women's awareness and knowledge regarding alcohol and cancer.

- A strength of the evaluation design was the inclusion of a baseline survey assessing women's knowledge and intentions concerning alcohol and cancer prior to the intervention.

- The use of cross-sectional tracking surveys without a control group did not allow for the contribution of secular trends to the results to be measured.

- The campaign advertisements have potential to be adapted for use and evaluation in other settings.

cancer, and knowledge of drinking guidelines.

However, a single campaign may be insufficient to measurably curb drinking behaviour in a culture where pro-alcohol social norms and product marketing are pervasive.

\section{INTRODUCTION}

Globally, alcohol consumption is a major risk factor contributing to the burden of ill health and premature death. An estimated $3.8 \%$ of deaths and $4.6 \%$ of disability adjusted lifeyears are attributable to alcohol use, and alcohol imposes economic costs equivalent to about $1 \%$ of gross national product in highincome countries. ${ }^{1}$ Alcohol is a known carcinogen, with current epidemiological data providing convincing evidence that alcohol is a cause of cancer of the mouth, pharynx, larynx, oesophagus, bowel (in men) and 
breast (in women), and probable evidence that it causes bowel cancer (in women) and liver cancer. ${ }^{2}$ There is also emerging evidence linking alcohol to pancreatic cancer ${ }^{3}$ and prostate cancer. ${ }^{4}$ It is estimated that, in Australia, up to 5663 cases of cancer (or $5.6 \%$ of all cancers) are attributable to long-term, chronic use of alcohol each year. ${ }^{5}$ Studies show a dose-response relationship between the amount of alcohol consumed and the chances of developing cancer. ${ }^{2}{ }^{6-8}$ Further, there is no evidence to indicate that cancer risk varies based on the type of alcoholic beverage consumed. ${ }^{2}$

Given that there is no safe level of alcohol consumption with respect to cancer, Cancer Council Australia (CCA) has recommended that people limit their alcohol intake or, better still, avoid alcohol altogether. ${ }^{5}$ For individuals who choose not to abstain, CCA supports drinking only within the National Health and Medical Research Council (NHMRC) Guidelines to Reduce Health Risks from Drinking Alcohol, which recommend no more than two standard drinks on any day to reduce alcoholrelated lifetime harm. ${ }^{9}$ A standard drink in Australia is defined as $10 \mathrm{~g}$ of alcohol (equivalent to $12.5 \mathrm{~mL}$ of pure alcohol). In 2010, 21\% of Australians aged 18 years or older reported consuming alcohol at levels that put them at risk of harm from alcohol-related disease or injury over their lifetime. ${ }^{10}$ Despite the salience of cancer within society, public awareness that alcohol causes cancer is generally low. ${ }^{11-13}$ Additionally, perceptions of the number of standard drinks an adult can drink every day without adversely affecting their health does not conform with guideline thresholds among the majority of Australians, ${ }^{14}$ with similar findings generally observed in other developed countries. ${ }^{15-17}$

There is a pressing need for population-based interventions that seek to increase community knowledge of the link between alcohol and cancer and recommended low-risk drinking levels. A 2008 survey in Western Australia found $55.6 \%$ of adult women, when prompted, recognised a link between alcohol consumption and cancer risk. In the same survey, $41.6 \%$ of women reported believing red wine consumption helped to prevent cancer. ${ }^{18}$ Mass media campaigns provide a highly costeffective means of reframing a particular health issue as a public health problem and promoting relevant behaviour change to a large audience. ${ }^{19}$ For example, road safety campaigns have been shown to be successful in reducing drunk driving. ${ }^{20}$ However, beyond this, past public information campaigns to reduce alcohol consumption have had little success when considered in isolation. ${ }^{21}$ There is also no scientific evidence regarding the effectiveness of the promotion of drinking guidelines in reducing alcohol-related harm. ${ }^{22}$ The Western Australian 'Alcohol and Cancer' campaign, launched in 2010, represents the first known paid mass media campaign that aims to increase awareness of the link between alcohol and cancer among women. Specifically, the campaign aimed to increase awareness of long-term risky drinking, particularly in relation to alcohol-caused cancer. The primary objectives of this study were to monitor awareness of the campaign and to determine changes in the target audience's knowledge and understanding that alcohol causes cancer, awareness of low-risk drinking in accordance with the NHRMC guidelines and concern about levels of alcohol consumption.

\section{METHODS \\ Design}

Cross-sectional tracking surveys conducted pre-intervention and post-intervention (waves I and III of campaign).

\section{Intervention}

The 'Alcohol and Cancer' mass media campaign was developed by the Western Australian Drug and Alcohol Office, in partnership with Cancer Council Western Australia, in response to findings from focus groups conducted with Western Australian women exploring their values, attitudes and beliefs around alcohol consumption. Eight focus groups were conducted with women aged 18-60 years, segmented by age and drinking behaviour. This formative research showed that the long-term health effects of drinking alcohol (including alcoholcaused cancer) were not well understood by adult women. ${ }^{23}$ Subsequently, the campaign target group for wave I was Western Australian women aged 25-54. People outside of Western Australia, women aged 55 years and over, and men, were excluded as they represent different media buying segments.

The mass media campaign comprised two television advertisements (TV ads) 'Spread' and 'Stains', supported by print ads, community posters, web-based information and unpaid media strategies. The 'Spread' ad depicted spilled red wine spreading out to form the shape of a woman's body, with the voice-over explaining that alcohol is carcinogenic and highlighting the specific cancer sites associated with risky drinking. The 'Stain' ad panned across a series of ring-shaped red wine stains on a white table cloth revealing the word 'cancer', as the voice-over explained that alcohol can cause particular types of cancer. Both ads included a text-frame stating "Have no more than two standard drinks on any day", which was referenced to the NHMRC. These ads can be viewed at http://www. alcoholthinkagain.com.au/Campaigns/Alcohol\%20and\% 20Cancer\%20Campaign.aspx. All campaign materials carried the Western Australian Drug and Alcohol Office's 'Alcohol. Think Again' umbrella brand and, where possible, were co-branded with Cancer Council Western Australia's logo.

Three waves of paid campaign advertising were conducted (see table 1). Wave I included both TV ads and supporting print ads. Waves II and III used only the 'Spread' TV ad. The level of paid TV advertising varied across the waves, as reflected by the Target Audience Rating Points (TARPs) booked and achieved. These estimates of audience size, collated by a commercial audience measurement provider, show the extent to which 
Table 1 Campaign waves and number of booked and achieved Target Audience Rating Points (TARPs)

\begin{tabular}{lllrr}
\hline Campaign wave & Dates & Advertisement(s) & $\begin{array}{l}\text { Number of TARPs } \\
\text { booked (statewide) }\end{array}$ & $\begin{array}{c}\text { Number of TARPs } \\
\text { achieved (statewide) }\end{array}$ \\
\hline Wave I & 16 May-17 July 2010 & Spread and Stains & 2375 & $2497\left(277 /\right.$ week $\left.^{*}\right)$ \\
Wave II & 17 October-12 November 2010 & Spread & 933 & $784\left(196 /\right.$ week $^{2}$ \\
Wave III & 10 April-28 May 2011 & Spread & 1858 & $1898(271 /$ week) \\
\hline
\end{tabular}

*Total TARPS averaged across campaign period, including some weeks where no TARPS were achieved.

the population in the media market would have been exposed to campaign advertisements on average each week. Higher TARP values mean more people saw the ad each week and/or it was shown more times.

\section{Population surveys}

Evaluation surveys were conducted in the month after waves I (survey 1) and III (survey 2) of the campaign, with baseline data collected at least a month prior to wave I (26 March-12 April, 2010). Wave II of the campaign was not separately evaluated, but is likely to have contributed to awareness and reactions to the campaign achieved following wave III. The three evaluation surveys (baseline, survey 1 and survey 2) were conducted online using identical sampling frames. Independent samples were sourced from an online database of Western Australian adults managed by the market research company commissioned to conduct the field work for the study (TNS Social Research, Perth). Ethics committee approval was not required for this low-risk public opinion survey. Invitations detailing the survey topic, length, incentives and privacy policy were emailed to eligible panellists to participate in the research. Incentives consisted of points, which could be redeemed for gift cards and vouchers. Panellists were excluded if they were: under the age of 25; resided outside Western Australia; or worked or had family member/s work in the areas of health promotion, alcohol sales or promotion, market research and/or police services. A brief description of the survey and a link to the online questionnaire were included in the invitation. The informed consent statement included advice to participants that their answers would be strictly confidential, that no individuals would be identified in the reporting of results and that privacy principles would be adhered to. To achieve representativeness and to ensure adequate representation of the primary target group (women aged 25-54 years), quotas were set by sex, age and geographic location. This paper reports on the evaluation results for women aged 25-54 years, since they were the primary target group for the campaign. Response rates were $21 \%$ for the baseline survey, $27 \%$ for the wave I survey and $35 \%$ for the wave II survey, which are typical for online surveys.

\section{Outcome measures}

The baseline and post-campaign surveys included a core set of common questions assessing knowledge, intentions and demographic characteristics. Drinking behaviour was determined by asking, "On average, over the past three months, on how many days in a normal week did you have an alcohol drink?", with responses ranging from '0 days, I don't drink alcohol' to '7 days a week'. Those who answered one or more days were then asked, "On average, over the past three months, how many standard drinks did you have on a day when you drank? A standard drink is a full-strength middy or stubby of mid-strength beer, a small glass of wine or one shot of standard spirits." Knowledge of the link between alcohol and cancer was assessed by asking, "Do you think eating or drinking any of the following types of food and beverages on a regular basis increases, decreases or has no effect on cancer risk?" Nineteen foods and beverages (including 'alcohol', 'red wine' and 'beer') were listed, with respondents indicating for each one whether it 'increases', 'decreases' or 'has no effect' on cancer risk. Knowledge of the NHMRC guideline promoted in the campaign was measured by asking respondents to identify the number of standard drinks that would be considered low risk in the long term.

A series of questions examined personal concerns, intentions and recent behaviour change regarding drinking among people who indicated they did drink: (1) "Are you concerned about the amount of alcohol you drink?", with responses recorded on a scale from $0=$ "not at all concerned' to $10=$ 'extremely concerned'; (2) "Would you like to drink less than you do currently?" with response options 'yes,... a lot less', 'yes,...slightly less' and 'no, I'm happy with the amount of alcohol I drink'; (3) "In the next three months, how likely or unlikely is it that you will reduce the amount of alcohol you drink?", with a response scale of $0=$ 'extremely unlikely' to $10=$ "extremely likely'; (4) "In the past three months, have you taken any steps to reduce the amount of alcohol you drink?", with 'yes' or 'no' response options.

The post-campaign surveys (surveys 1 and 2) included an additional section at the end assessing awareness and reactions to the campaign $\mathrm{TV}$ ad/s. Campaign recall (unprompted) was measured by asking respondents to describe any ads they remembered hearing or seeing on TV recently about the health impacts of alcohol. Respondents were coded as having recalled the campaign if they provided a description that was definitely the 'Spread' ad (eg, effects of excessive alcohol on internal organs, anatomical figure in red) at survey 1 or 2, or definitely the 'Stains' ad (eg, wine stains spelling cancer, red wine glass marks) at survey 1. Campaign 
recognition (prompted) was measured by playing the ad in full twice, then asking, "Had you seen this ad before today over the past few months or so?" Survey 1 respondents were shown both the 'Spread' and 'Stains' ads (in random order and separated by questions about their reactions to the first ad they viewed), while all survey 2 respondents were shown the 'Spread' ad.

Prompted message takeout was assessed by asking respondents who recognised the campaign, "Which of these messages do you recall being in this ad?", before presenting them with the following three statements in random order: (1) There is a link between drinking alcohol and getting cancer; (2) The more alcohol you drink, and the more often, the greater your risk of cancer; (3) You can stay at low risk of developing cancer by drinking no more than two standard drinks on a regular basis. Response options were 'yes', 'no' and 'don't know'. Recall of the drinking recommendations presented in the ad was assessed by asking, "Can you recall after how many drinks the ad says a person is no longer at low risk of getting cancer and other alcoholcaused diseases?" Response options were "no more than...2, 3, 4 or 5' respectively, 'more than 5' and 'don't know/unsure'. Personal motivation in response to the ad (among drinkers only) was assessed by asking, "As a result of seeing this ad, how motivated do you feel to reduce your own alcohol consumption?", with response options of 'very', 'somewhat', 'not at all' and 'don't know'. Concern about others drinking was assessed by asking, "As a result of seeing this ad, how concerned are you about the amount of alcohol that people in your social circles drink?” Response options for this question were 'very', 'a little', 'not at all' and 'don't know'.

\section{Statistical analysis}

Data were analysed using Stata SE V.12.1 (StataCorp, Texas, USA) and weighted to population levels on age, sex and place of residence. $\chi^{2}$ analyses were conducted to determine whether sample demographic characteristics differed at each evaluation survey. Each of the primary response variables were dichotomised for analysis purposes (see tables 3-5). Scores on the items assessing personal concern and intentions (scored 0-10) were dichotomised to indicate responses in the desired direction (>5). Separate logistic regression analyses examined differences by evaluation survey in awareness and reactions to the campaign (survey 1 vs survey 2), and knowledge and intentions (baseline vs survey 1; baseline vs survey 2). Interactions between drinking behaviour and evaluation survey were tested, but as none were found to be significant, they were not retained in the final models. Main effects of drinking behaviour ( $\leq 2$ standard drinks per day of $>2$ standard drinks per day) were explored for all questions asked of only women who drank alcohol. Separate logistic regression analyses examined differences by campaign awareness in knowledge and intentions (survey 1 and 2 results combined). All models controlled for age group, location, education level, household composition and drinking behaviour. There were no missing data on any of the variables except drinking status, where less than $4 \%$ of respondents per survey declined from answering this

\begin{tabular}{|c|c|c|c|c|}
\hline Characteristic & $\begin{array}{l}\text { Baseline ( } n=136) \\
\text { Per cent }\end{array}$ & $\begin{array}{l}\text { Survey } 1(n=206) \\
\text { Per cent }\end{array}$ & $\begin{array}{l}\text { Survey } 2(n=155) \\
\text { Per cent }\end{array}$ & Test statistic \\
\hline Age group & & & & $\chi^{2}(4)=0.65, p=0.957$ \\
\hline $25-34$ years & 29.4 & 31.1 & 32.3 & \\
\hline $35-44$ years & 39.7 & 36.4 & 35.5 & \\
\hline $45-54$ years & 30.9 & 32.5 & 32.3 & \\
\hline Location & & & & $\chi^{2}(2)=1.69, p=0.430$ \\
\hline Metropolitan & 70.6 & 76.7 & 72.9 & \\
\hline Non-metropolitan & 29.4 & 23.3 & 27.1 & \\
\hline Education level & & & & $\chi^{2}(2)=4.19, p=0.123$ \\
\hline Did not complete tertiary & 71.3 & 76.2 & 66.5 & \\
\hline Completed tertiary & 28.7 & 23.8 & 33.5 & \\
\hline Household composition & & & & $\chi^{2}(6)=14.19, p=0.028$ \\
\hline Couple with child(ren) & 56.6 & 60.7 & 49.0 & \\
\hline Couple with no children & 12.5 & 13.6 & 25.2 & \\
\hline One parent family with child(ren) & 8.8 & 10.2 & 7.1 & \\
\hline Single or other & 22.1 & 15.5 & 18.7 & \\
\hline Drinking behaviour* & & & & $\chi^{2}(4)=2.23, p=0.693$ \\
\hline Non-drinker & 31.9 & 37.2 & 37.3 & \\
\hline$\leq 2$ standard drinks per day $\dagger$ & 42.2 & 38.2 & 34.7 & \\
\hline$>2$ standard drinks per dayt & 25.9 & 24.6 & 28.0 & \\
\hline
\end{tabular}


Table 3 Proportion of respondents aware of the 'Alcohol and Cancer' campaign and their reactions to it following waves I and III of the campaign

\begin{tabular}{|c|c|c|}
\hline & $\begin{array}{l}\text { Survey } 1 \\
\text { Per cent }\end{array}$ & $\begin{array}{l}\text { Survey } 2 \\
\text { Per cent }\end{array}$ \\
\hline Campaign awareness & $(n=206)$ & $(n=155)$ \\
\hline Recall (unprompted) & 27.8 & 34.9 \\
\hline Recognition (prompted)* & 67.5 & $81.2 \dagger$ \\
\hline Reactions to the campaign among those who recognised the television advertisement & $(n=119) \ddagger$ & $(n=126)$ \\
\hline Prompted recall of message 1: 'There is a link between drinking alcohol and getting cancer' & 91.3 & 95.6 \\
\hline $\begin{array}{l}\text { Prompted recall of message 2: 'The more alcohol you drink, and the more often, the greater your } \\
\text { risk of cancer' }\end{array}$ & 78.1 & 81.8 \\
\hline $\begin{array}{l}\text { Prompted recall of message 3: 'You can stay at low risk of developing cancer by drinking no more } \\
\text { than two standard drinks on a regular basis' }\end{array}$ & 75.7 & $90.1 \dagger$ \\
\hline Recall correct number of drinks (two) mentioned in television advertisement & 92.0 & 94.0 \\
\hline As a result of seeing the ad, I feel motivated to reduce my own alcohol consumption§ & 48.6 & 49.8 \\
\hline $\begin{array}{l}\text { As a result of seeing the ad, I am concerned about the amount of alcohol people in my social circles } \\
\text { drink }\end{array}$ & 77.7 & 80.9 \\
\hline \multicolumn{3}{|c|}{$\begin{array}{l}\text { *Recognition of Spread and/or Stains for survey } 1 \text { respondents and recognition of Spread for survey } 2 \text { respondents. } \\
\text { †Significantly different to survey } 2 \text { at } p<0.05 \text { level after controlling for age group, location, education level, household composition and drinking } \\
\text { behaviour. } \\
\text { †For survey } 1 \text {, these questions were only asked of those respondents who recognised the first of two campaign advertisements they were } \\
\text { randomly shown. } \\
\text { §Question not asked of non-drinkers. }\end{array}$} \\
\hline
\end{tabular}

question. These cases were excluded from the multivariate analyses.

\section{RESULTS}

Sample characteristics

The samples surveyed in each phase comprised similar distributions for all demographic characteristics except household composition (see table 2). For survey 2, there were more couples with no children. Around one-third of respondents were non-drinkers, while approximately one in four reported having, on average, more than two standard drinks on days when they consumed alcohol.

\section{Campaign awareness and message takeout}

As table 3 highlights, unprompted recall of the campaign was $28 \%$ at survey 1 and $35 \%$ at survey 2, with this slight increase not statistically significant (adjusted OR $(\operatorname{adj}$ OR $)=1.29,95 \%$ CI 0.80 to $2.08, \mathrm{p}=0.297)$. However, prompted recognition was significantly higher among women at survey 2 compared with survey 1 (81\% cf $67 \%$; adj $\mathrm{OR}=2.31,95 \%$ CI 1.33 to $4.00, \mathrm{p}=0.003$ ).
Of those who recognised the campaign, over threequarters were able to recall each of the three key messages in the ad when prompted. The most recognised campaign message was that "There is a link between drinking alcohol and getting cancer". In addition, prompted recall of the message that "You can stay at low risk of developing cancer by drinking no more than two standard drinks on a regular basis" improved significantly from survey 1 to survey 2 among women who recognised the campaign (adj OR $=3.30,95 \%$ CI 1.38 to $7.90, \mathrm{p}=0.008$ ). For both surveys, nearly all women who recognised the campaign recalled the correct number of drinks mentioned in the ad while around 8 in 10 of these women indicated they were concerned (either very or a little) about the amount of alcohol that people in their social circles drink as a result of seeing the ad. Approximately half the women who drank alcohol and recognised the campaign reported that the ad made them feel motivated (either very or somewhat) to reduce their own alcohol consumption. Further, women who drank more than two standard drinks on days when

Table 4 Proportion of respondents demonstrating knowledge of link between alcohol and cancer risk

\begin{tabular}{|c|c|c|c|}
\hline & $\begin{array}{l}\text { Baseline }(n=136) \\
\text { Per cent }\end{array}$ & $\begin{array}{l}\text { Survey } 1(n=206) \\
\text { Per cent }\end{array}$ & $\begin{array}{l}\text { Survey } 2(n=155) \\
\text { Per cent }\end{array}$ \\
\hline Drinking alcohol on a regular basis increases cancer risk & 62.4 & $80.5^{\star}$ & $87.4^{*}$ \\
\hline Drinking red wine on a regular basis increases cancer risk & 20.5 & $39.5^{*}$ & $44.8^{*}$ \\
\hline Drinking beer on a regular basis increases cancer risk & 49.0 & $69.7^{*}$ & $79.3^{*}$ \\
\hline $\begin{array}{l}\text { The guidelines recommend drinking two or less standard } \\
\text { drinks for low risk in the long-term }\end{array}$ & 62.0 & $72.8^{*}$ & 68.8 \\
\hline
\end{tabular}


Table 5 Proportion of respondents expressing personal concern, positive intentions and recent behaviour change by drinking behaviour*

\begin{tabular}{|c|c|c|c|c|c|c|}
\hline & \multicolumn{2}{|l|}{ Baseline } & \multicolumn{2}{|l|}{ Survey 1} & \multicolumn{2}{|l|}{ Survey 2} \\
\hline & \multicolumn{6}{|c|}{ Number of standard drinks per day (\%) } \\
\hline & $\leq 2(n=57)$ & $>2(n=35)$ & $\leq 2(n=76)$ & $>2(n=49)$ & $\leq 2(n=52)$ & $>2(n=42)$ \\
\hline Concerned about the amount of alcohol you drink $†$ & 7.0 & 25.1 & 5.6 & 21.1 & 15.9 & 32.6 \\
\hline Likely I will reduce the amount of alcohol I drink†‡ & 9.7 & 28.0 & 8.2 & 31.4 & 24.5 & 38.5 \\
\hline Would like to drink less than currently $\dagger$ & 10.8 & 40.2 & 13.9 & 28.6 & 21.7 & 43.4 \\
\hline $\begin{array}{l}\text { In the past } 3 \text { months, have taken steps to reduce } \\
\text { the amount of alcohol you drink } \dagger\end{array}$ & 9.0 & 27.9 & 11.1 & 26.3 & 16.4 & 29.7 \\
\hline
\end{tabular}

they consumed alcohol were more likely to report that the ad made them feel motivated to reduce their own alcohol consumption, compared with those who drank at lower levels $(64 \%$ cf $38 \%$; adj $\mathrm{OR}=3.45,95 \%$ CI 1.66 to $7.17, \mathrm{p}=0.001)$.

\section{Knowledge and intentions towards alcohol}

As shown in table 4, significant increases in the proportion of women who knew that drinking alcohol on a regular basis increases cancer risk were found at survey 1 $($ adj $\mathrm{OR}=2.60,95 \%$ CI 1.57 to $4.30, \mathrm{p}<0.001)$ and survey 2 (adj $\mathrm{OR}=4.88,95 \%$ CI 2.55 to $9.36, \mathrm{p}<0.001)$ compared with baseline. Similarly, the proportion of women who knew of the link between drinking beer and cancer risk was significantly higher among survey 1 (adj $\mathrm{OR}=2.44,95 \%$ CI 1.53 to $3.88, \mathrm{p}<0.001$ ) and survey 2 (adj $\mathrm{OR}=4.19,95 \%$ CI 2.44 to $7.22, \mathrm{p}<0.001$ ) respondents compared with baseline. Only one in five women at baseline reported being aware that drinking red wine on a regular basis increases cancer risk. While this increased significantly at survey 1 (adj $\mathrm{OR}=2.57,95 \%$ CI 1.53 to $4.33, \mathrm{p}<0.001)$ and survey 2 (adj $\mathrm{OR}=3.24,95 \%$ CI 1.85 to $5.65, \mathrm{p}<0.001)$, more than half the women surveyed $(55 \%)$ were still unaware of the link between red wine and cancer risk after wave III of the campaign. There was a significant increase in the proportion of women who knew the recommended number of standard drinks for low risk in the long term from baseline to survey $1(\operatorname{adj} \mathrm{OR}=1.68,95 \%$ CI 1.02 to $2.76, \mathrm{p}=0.041)$, but not baseline to survey 2 (adj $\mathrm{OR}=1.42,95 \%$ CI 0.84 to $2.39, \mathrm{p}=0.191$ ).

Across all surveys, women who consumed higher levels of alcohol ( $>2$ standard drinks per day) were significantly more likely to be concerned about the amount of alcohol they drink and to express positive intentions for reducing their alcohol intake than women who drank less (see table 5). There was also a significant overall increase from baseline to survey 2 in the proportion of women who drank alcohol indicating they will be likely to reduce their consumption ( $17 \%$ cf $30 \%$; adj $\mathrm{OR}=2.38$, $95 \%$ CI 1.11 to $5.12, \mathrm{p}=0.026)$. However, the proportion who endorsed the other three statements did not increase significantly following the campaign for heavy or light drinkers.

As shown in figure 1, a significantly higher proportion of respondents who were aware of the campaign knew of the links between cancer and alcohol (adj $\mathrm{OR}=4.11$, 95\% CI 2.15 to $7.85, \mathrm{p}<0.001$ ), wine (adj OR=1.87, 95\% CI 1.11 to $3.16, p=0.019)$ and beer $(\operatorname{adj} \mathrm{OR}=3.54,95 \%$ CI 2.02 to $6.20, \mathrm{p}<0.001)$ respectively, and of the drinking guidelines (adj OR=2.28, 95\% CI 1.34 to 3.88, $\mathrm{p}=0.003$ ) compared with those not aware of the campaign. However, personal concern, intentions for drinking and changes to recent drinking behaviour did not differ significantly for those drinkers who were aware and not aware of the campaign (all $\mathrm{p}>0.05$ ).

\section{DISCUSSION}

\section{Principal findings}

The results of this study indicate that the Western Australian 'Alcohol and Cancer' campaign was recognised by the majority of its target audience, with prompted recall

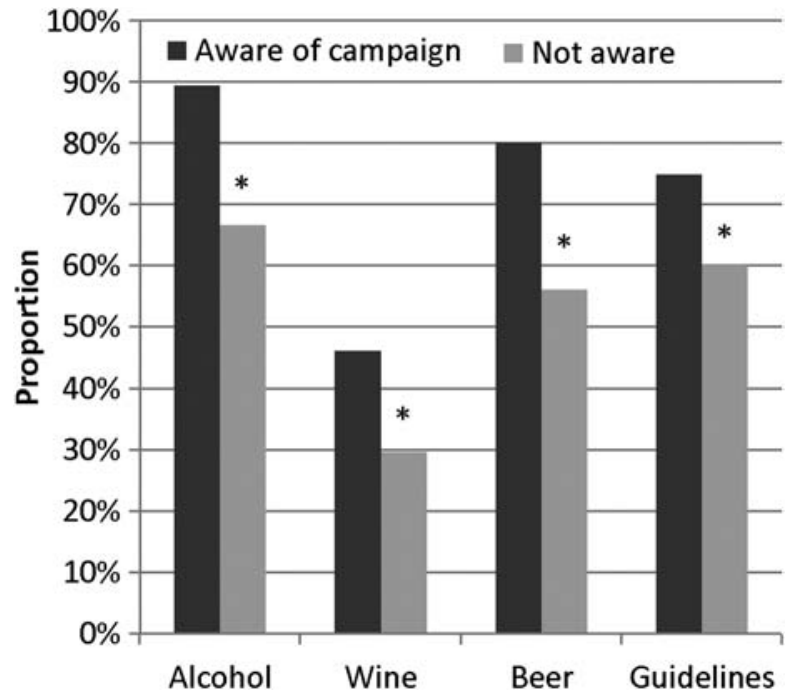

Figure 1 Knowledge of the link between alcohol and cancer, and of drinking guidelines among survey 1 and 2 respondents for those aware and not aware of the 'Alcohol and Cancer' campaign. ${ }^{*}$ Significant difference at $p<0.05$ level. 
of its key messages high among those who had been exposed to the campaign. Campaign reach increased between waves I and III, suggesting the latter campaign waves built on the good level of campaign awareness established initially. This is pleasing given the media buys were smaller for each of the latter two waves compared with the first. Importantly, the campaign achieved its primary objective of increasing awareness of the link between drinking alcohol and cancer among women aged 25-54 years. We also found some evidence to show that knowledge of the NHMRC guidelines for low-risk drinking improved after wave I of the campaign. Women who drank more than two standard drinks per day were the most likely to say the ad made them feel more motivated to reduce their drinking, suggesting the ad caused them to accurately reflect on their alcohol consumption relative to the guidelines. In the early stages of a campaign such as this, improvements in knowledge and awareness are positive initial outcomes. It is especially encouraging that among women who drink alcohol, the proportion intending to reduce their alcohol consumption increased significantly following the campaign. However, no significant reductions in the more distal outcome of recent drinking behaviour were found following the campaign among heavy or light drinkers. Aside from mass media campaigns to reduce drunk driving, campaigns to reduce alcohol intake have, to date, demonstrated little success in changing behaviour, probably because the potential benefits have typically been overshadowed by widespread alcohol marketing and pro-drinking social norms. ${ }^{19}$ Encouraging people to reduce alcohol consumption in an environment where competing product advertising and social norms pervade ${ }^{24}$ is a difficult task. To achieve real reductions in alcohol consumption, sustained education about the harms of alcohol needs to occur within a broader policy programme of pricing controls, restrictions on alcohol availability and regulating promotion. ${ }^{25}$ Around the time of this campaign, there was active debate on alcohol policy issues in Western Australia through the establishment of the McCusker Centre for Alcohol and Youth, and the Alcohol, Advertising Review Board. Neither of these initiatives focused specifically on the link between alcohol and cancer.

\section{Comparison with other studies}

This study represents the first published evaluation of a mass media campaign highlighting the link between alcohol and cancer. Results indicate this innovative mass media intervention produced medium to large effects ${ }^{26}$ on improving women's awareness and knowledge. Recently, a UK alcohol awareness organisation (Balance) broadcasted a TV ad in the north-east of England that depicts a tumour growing in a glass of beer a man is drinking to illustrate the message that alcohol increases a person's risk of cancer. ${ }^{27}$ Unpublished evaluation survey results (face-to-face interviews conducted post-campaign, $\mathrm{N}=420$ men and women) found just over half the respondents showed unprompted awareness and prompted awareness, with higher prompted awareness among women than men (60\% vs $48 \%$ ). Prompted awareness levels among women were similar following the first wave of campaign activity for the Australian and UK campaigns, despite their different advertisements and survey methodologies. Respondents took out similar messages from the UK advertisement as for the Australian ads, most commonly reporting the link between drinking alcohol and getting cancer, and the recommendation to drink less alcohol. Both evaluations found that respondents aware of the campaign showed better knowledge of the link between alcohol and cancer than those not aware of the campaign. In 2012, the Danish Ministry of Health aired an ad targeting Danish citizens with the message that drinking too much alcohol increases the risk for cancer. We have not been able to obtain evaluation results for this campaign. Together, available results indicate that televised public health campaigns are effective for improving community knowledge that alcohol is carcinogenic.

\section{Strengths and limitations of the study}

A strength of this pre-intervention and post-intervention evaluation design was that it included baseline assessment of women's knowledge and intentions concerning alcohol and cancer. However, the absence of a control group was a limitation, in that the contribution of secular trends to the results could not be measured. So too was the modest sample size, which was not adequately powered to detect small effects (ORs of about 1.5) ${ }^{26}$ These limitations were due to the limited evaluation budget for the study, which did not provide scope to survey a comparable, unexposed control sample or larger cross-sectional samples. An alternative for tracking changes following the campaign would have been to survey a cohort pre-intervention and postintervention. However, a limitation of that approach would be that undertaking the baseline survey could prime respondents' subsequent self-reports. The changes in beliefs that occurred pre-campaign and post-campaign were very specific to those addressed in the campaign advertisements, supporting the notion that these changes were not merely a reflection of secular trends. The simple, single item measures used to assess personal drinking concerns, intentions and recent behaviour change could have been less sensitive to detecting change than if multiple questions were used to assess these constructs. However, given budget restraints and the need to minimise response burden for participants, it was necessary to limit the total number of survey questions. A further limitation of the study was the low response rate, which is typical of online surveys, and could compromise the generalisability of the findings. To address this issue, quotas were set for the sampling frame to improve representativeness, and analyses were adjusted for demographic variables to reduce the potential for confounding.

\section{Meaning of the study: possible explanations and implications for clinicians and policymakers}

This study provides empirical evidence for the value of a social marketing campaign highlighting the link 
between alcohol and cancer for improving public awareness that alcohol causes cancer, and of promulgating public health guidelines to reduce the health risks from drinking alcohol. The campaign advertisements have potential to be adapted for use and evaluation in other settings. This has occurred with the advertisement being translated and aired in Finland by the Cancer Society of Finland.

\section{Unanswered questions and future research}

Future research could examine the campaign's longer term impact on alcohol-related knowledge, attitudes and behaviour in the primary target group, and in other population segments. As other countries begin to run mass media campaigns highlighting the link between alcohol and cancer, it will be important to publish evaluation results for these campaigns too. Where feasible, it would be useful to include a control group in the evaluation design, as well as pre-campaign and post-campaign measures.

\section{Twitter Follow lain Pratt at @pratt_steve}

Acknowledgements The authors thank TNS Social Research (Perth) for coordinating data collection.

Contributors HGD supervised the data analysis and made substantial contributions to interpreting the data, and writing and critically revising the manuscript. ISP contributed substantially to the design and implementation of the intervention, design and methods of the evaluation, and drafting the manuscript and revising it. MLS conducted the data analysis and contributed substantially to interpreting the data, and writing and critically revising the manuscript. JRM contributed substantially to data management, and provided valuable assistance with data analysis and revising the paper. CP oversaw and contributed significantly to the design and implementation of the intervention, and contributed to writing and revising the manuscript. $\mathrm{RH}$ contributed to interpreting the data, and writing and revising the manuscript.

TJS contributed substantially to the design and implementation of the intervention, the design and methods of the evaluation, and with writing the manuscript.

Funding The intervention campaign and the evaluation research was funded by the Government of Western Australia through the Western Australian Drug and Alcohol Office.

Competing interests All authors have completed the ICMJE uniform disclosure at http://www.icmje.org/coi_disclosure.pdf (available on request from the corresponding author) and declare: financial support for the submitted work from their respective employers, Cancer Council Western Australia (ISP and TJS), Cancer Council Victoria (HGD, MLS) and Drug and Alcohol Office, Government of Western Australia (JRM, CP, RH).

Ethics approval The study was conducted in accordance with the ethical guidelines of the Australian Market and Social Research Society's (AMSRS) Code of Professional Behaviour, the National Privacy Principles (1988) and the Australian Privacy Principles (March 2014) as applicable to the Market and Social Research Industry (AMSRO Code).

Provenance and peer review Not commissioned; externally peer reviewed.

Data sharing statement No additional data are available.

Open Access This is an Open Access article distributed in accordance with the Creative Commons Attribution Non Commercial (CC BY-NC 4.0) license, which permits others to distribute, remix, adapt, build upon this work noncommercially, and license their derivative works on different terms, provided the original work is properly cited and the use is non-commercial. See: http:// creativecommons.org/licenses/by-nc/4.0/

\section{REFERENCES}

1. Rehm J, Mathers C, Popova S, et al. Global burden of disease and injury and economic cost attributable to alcohol use and alcohol-use disorders. Lancet 2009;373:2223-33.

2. World Cancer Research Fund, American Institute for Cancer Research. Food, nutrition, physical activity, and the prevention of cancer: a global perspective. Washington, USA: American Institute for Cancer Research, 2007.

3. Secretan B, Straif K, Baan R, et al. A review of human carcinogens -part E: tobacco, areca nut, alcohol, coal smoke, and salted fish. Lancet Oncol 2009;10:1033-4.

4. Middleton Fillmore K, Chikritzhs T, Stockwell T, et al. Alcohol use and prostate cancer: a meta-analysis. Mol Nutr Food Res 2009;53:240-55.

5. Winstanley MH, Pratt IS, Chapman K, et al. Alcohol and cancer: a position statement from Cancer Council Australia. Med $J$ Aust 2011;194:479-82.

6. Corrao G, Bagnardi V, Zambon A, et al. A meta-analysis of alcohol consumption and the risk of 15 diseases. Prev Med 2004;38:613-19.

7. Hamajima N, Hirose K, Tajima K, et al. Alcohol, tobacco and breast cancer-collaborative reanalysis of individual data from 53 epidemiological studies, including 58,515 women with breast cancer and 95,067 women without the disease. Br J Cancer 2002;87:1234-45.

8. Allen NE, Beral V, Casabonne D, et al. Moderate alcohol intake and cancer incidence in women. J Natl Cancer Inst 2009;101:296-305.

9. National Health and Medical Research Council. Australian guidelines to reduce health risks from drinking alcohol. Canberra, Australia, 2009.

10. Australian Institute of Health and Welfare. 2010 National Drug Strategy Household Survey report. Canberra, Australia: Australian Institute of Health and Welfare, 2011.

11. Bowden JA, Delfabbro P, Room R, et al. Alcohol consumption and NHMRC guidelines: has the message got out, are people conforming and are they aware that alcohol causes cancer? Aust $N$ Z J Public Health 2014;38:66-72.

12. Hill D, Wakefield M. Understanding and influencing cancer-related beliefs and behaviour can improve outcome. Lancet Oncol 2008:9:1020-1.

13. Hawkins NA, Berkowitz Z, Peipins LA. What does the public know about preventing cancer? Results from the Health Information National Trends Survey (HINTS). Health Educ Behav 2010;37:490-503.

14. Livingston M. Perceptions of low-risk drinking levels among Australians during a period of change in the official drinking guidelines. Drug Alcohol Rev 2012;31:224-30.

15. Sellman JD, Ariell GW. Public knowledge and attitudes towards the use of alcohol and drinking guidelines. N Z Med J 1996;109:337-9.

16. Bendtsen $\mathrm{P}$, Karlsson N, Dalal K, et al. Hazardous drinking concepts, limits and methods: low levels of awareness, knowledge and use in the Swedish population. Alcohol Alcohol 2011;46:638-45.

17. de Visser RO, Birch JD. My cup runneth over: young people's lack of knowledge of low-risk drinking guidelines. Drug Alcohol Rev 2012;31:206-12.

18. MacTiernan A, Fritschi L, Slevin T, et al. Public perceptions of cancer risk factors: a Western Australian study. Health Promot $J$ Austr 2014;25:90-6.

19. Wakefield M, Loken B, Hornik R. Use of mass media campaigns to change health behaviour. Lancet 2010;376:1261-71.

20. Elder RW, Shults RA, Sleet DA, et al. Effectiveness of mass media campaigns for reducing drinking and driving and alcohol-involved crashes: a systematic review. Am J Prev Med 2004;27:57-65.

21. Babor T, Caetano R, Casswell S, et al. Alcohol: no ordinary commodity. 2nd edn. New York: Oxford University Press, 2010.

22. Anderson P, Chisholm D, Fuhr DC. Effectiveness and cost-effectiveness of policies and programmes to reduce the harm caused by alcohol. Lancet 2009;373:2234-46.

23. TNS Social Research. Risky drinking: a qualitative exploration of women's values, attitudes and beliefs around alcohol consumption. Prepared for Government of Western Australia Drug and Alcohol Office. Subiaco, Australia: TNS Social Research, 2009.

24. Pettigrew S, Roberts M, Pescud M, et al. The extent and nature of alcohol advertising on Australian television. Drug Alcohol Rev 2012;31:797-802.

25. National Preventive Health Taskforce (Alcohol Working Group). Preventing alcohol-related harm in Australia: a window of opportunity. Canberra: Australian Government Department of Health and Ageing, 2008.

26. Rosenthal JA. Qualitative descriptors of strength of association and effect size. J Soc Serv Res 1996:21:37-59.

27. Gornall J. TV advertisement that linked alcohol with cancer was not misleading, says UK regulator. BMJ 2014;348:g2793. 